\title{
АНАЛИЗ РАСХОЖДЕНИЙ СТАТИСТИЧЕСКИХ ДАННЫХ ПО ВНЕШНЕЭКОНОМИЧЕСКОЙ ДЕЯТЕЛЬНОСТИ РОССИЙСКОЙ ФЕДЕРАЦИЕЙ И ЕЕ КЛЮЧЕВЫХ ТОРГОВЫХ ПАРТНЕРОВ *
}

\author{
(C) 2021 Бурцева К.Ю. \\ кандидат экономических наук, доцент Департамента бизнес-аналитики \\ Финансовый университет при Правительстве Российской Федерации, Россия, Москва \\ E-mail: aksentiya@mail.ru
}

Статистические данные внешнеэкономической деятельности не только отражают эффективность взаимодействия субъектов экономической деятельности, вступающих в партнерские связи, но и являются основой для функционирования и поддержания всей системы международных торговых связей. В статье проанализированы данные, подтверждающие двустороннюю асимметрию сведений внешнеэкономической деятельности Российской Федерацией и ее ключевых торговых партнеров, в частности рассмотрено расхождение в статистике торговли России и Китая. Установлены причины несоответствия данных о взаимных торгово-экономических отношениях.

Ключевые слова: Россия, Китай, внешнеэкономическая деятельность, статистика, расхождение статистики, сотрудничество, торговое сотрудничество.

Статистические данные с целью их общественной «полезности» должны поддерживать глобальную инициативу по сбалансированности статистики торговли и включать достоверную информацию. Одним из основных критериев, требующих соблюдения во внешнеэкономической деятельности - это согласованность во времени и между странами. Данное исследование посвящено изучению проблемного вопроса расхождения между данными внешнеэкономических показателей торговли России и ее партнеров.

Проблема расхождения во внешнеэкономических показателях торговли заключается в разнице данных по экспорту одной страны и импорту ее партнера (на практике такая разница может иметь значительную доли всего объема внешнеторговых операций).

Существуют различные базы статистических данных по показателям внешнеэкономической деятельности многих стран мира, поддерживаемые и составляемые международными организациями. Данные организации собирают и анализируют сведения национальных статистических учреждений и национальных агентств. Для регулярного сопоставления сведений о внешней торговли России с ее ключевыми партнерами можно использовать базы данных: Федеральной таможенной службы, МВФ, Евростат,
Межгосударственного статистического комитета СНГ, а также Организации Объединенных Наций. Исследование всех вышеперечисленных источников свидетельствует о наличии как системных, так и внесистемных расхождений.

Поскольку международные статистические организации не в состоянии установить достоверность, предоставляемых разными странами стоимость экспортируемых и импортируемых товаров, проблема торговой асимметрии является весьма актуальной для аккумулирующих данные агентств, стремящихся к улучшению согласованности информационных баз данных. Проблема расхождения статистики внешнеэкономической деятельности также затрагивает интересы аналитиков и исследователей, изучающих двусторонние потоки между торговыми партнерами.

В настоящее время существуют огромное количество официальных ресурсов, предоставляющих данные о международной торговле. Однако, если сравнить различные источники, можно обнаружить не состыковку данных. Акцентируя внимание на определенном показателе в выбранный период времени в одной и той же стране в разных источниках прослеживаются значительные расхождения.

На рисунке 1 представлена доля экспорта и импорта Российской Федерации и ее торговых

\footnotetext{
* Статья подготовлена по результатам исследований, выполненных за счет средств по государственному заданию Финуниверситета
} 


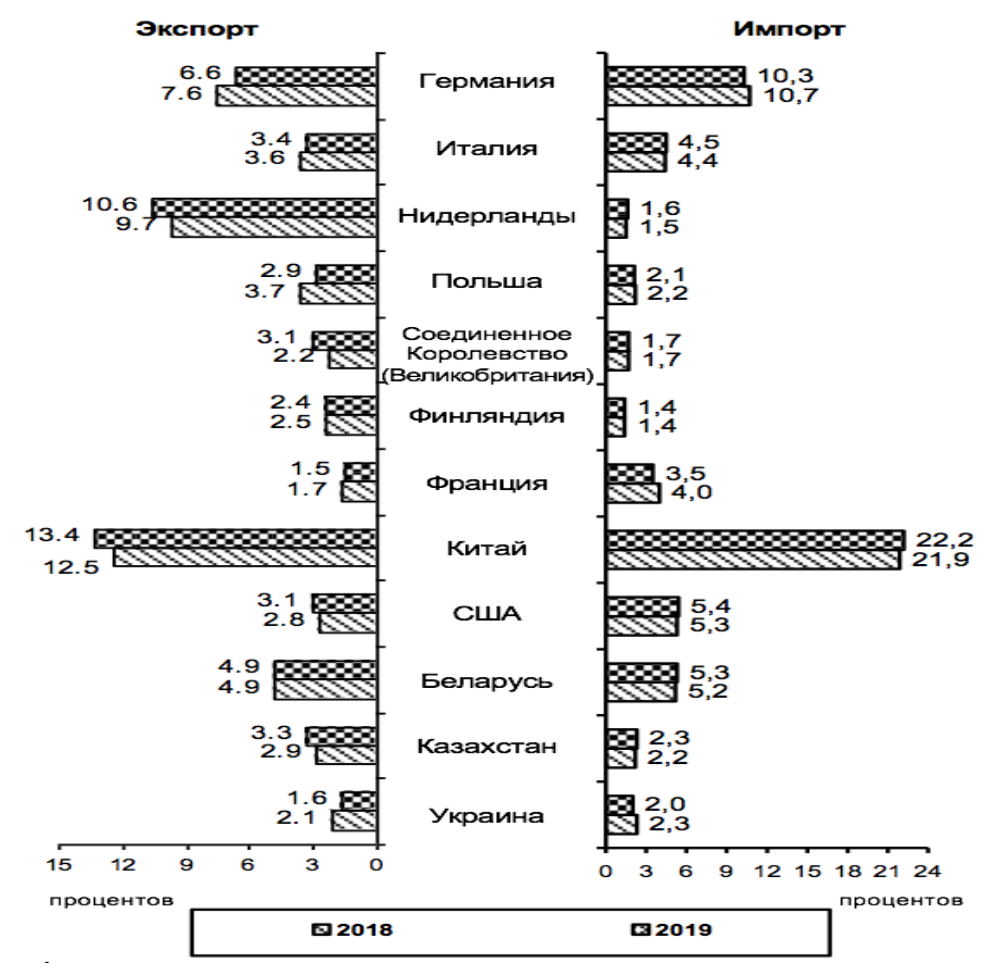

Рисунок 1. Экспорт и импорт РФ по ряду зарубежных стран,\% Источник: Росстат [7]

партнеров в 2018-2019 гг. Исходя из такого значимого веса во внешнеторговых отношениях, приходящегося на Китай, данная страна требует особого внимания. Рассмотрим расхождение в статистике внешнеэкономических данных торговли России и Китая.

В течении многих лет Китай был и остается сейчас одним из важнейших с точки зрения объемов сделок партнером Российской Федерации. Торговля между ключевыми партнерскими странами ведется по различным направлениям, начиная от продуктов сельскохозяйственной деятельности и изделий, сделанных из древесины, и заканчивая нефтепродуктами. По состоянию на 2019 год суммарный экспорт в Китай достиг $13.4 \%$ от общего экспорта Российской Федерации (рисунок 1), в то время как импорт составил $22.2 \%$ от совокупного импорта на 2019 год.
Чтобы удостовериться в несоответствии данных, необходимо проверить действительно ли статистика об экспорте и импорте Российской Федерации в страны-партнеры имеет расхождения. Для этого рассмотрим данные трех различных российских источников: Рустат (rustat) [6], Министерства экономического развития (ved.gov) [5] и базы данных Trade economy (trendeconomy) [2]. Сверим статистику данных источников с 2016 по 2019 гг. в таблице 1.

Анализируя статистические данные, можно обратить внимание, что прослеживаются значительные расхождения в данных трех исследованных источников. Для наглядности представления такого расхождения построен рисунок 2 .

Далее рассмотрим сведения базы данных, составляемой Организацией Объединенных Наций [1], и составим график, отображающий

Таблица 1. Данные об экспорте России в Китай с 2016 по 2019 гг.

\begin{tabular}{|c|c|c|c|}
\hline \multirow{2}{*}{ Год } & \multicolumn{3}{|c|}{ Сумма млн. долл. США, согласно источнику } \\
\cline { 2 - 4 } & Рустат (ru-stat) & $\begin{array}{c}\text { Министерство экономиче- } \\
\text { ского развития (ved.gov) }\end{array}$ & $\begin{array}{c}\text { База данных Trade economy } \\
\text { (trendeconomy) }\end{array}$ \\
\hline 2016 & 25900000000 & н\д & 29953376571 \\
\hline 2017 & 38900000000 & н\д & 41671349422 \\
\hline 2018 & 56000000000 & 56019400000 & 56019903783 \\
\hline 2019 & 57300000000 & 57322000000 & 57321295775 \\
\hline
\end{tabular}

Источник: составлено автором 


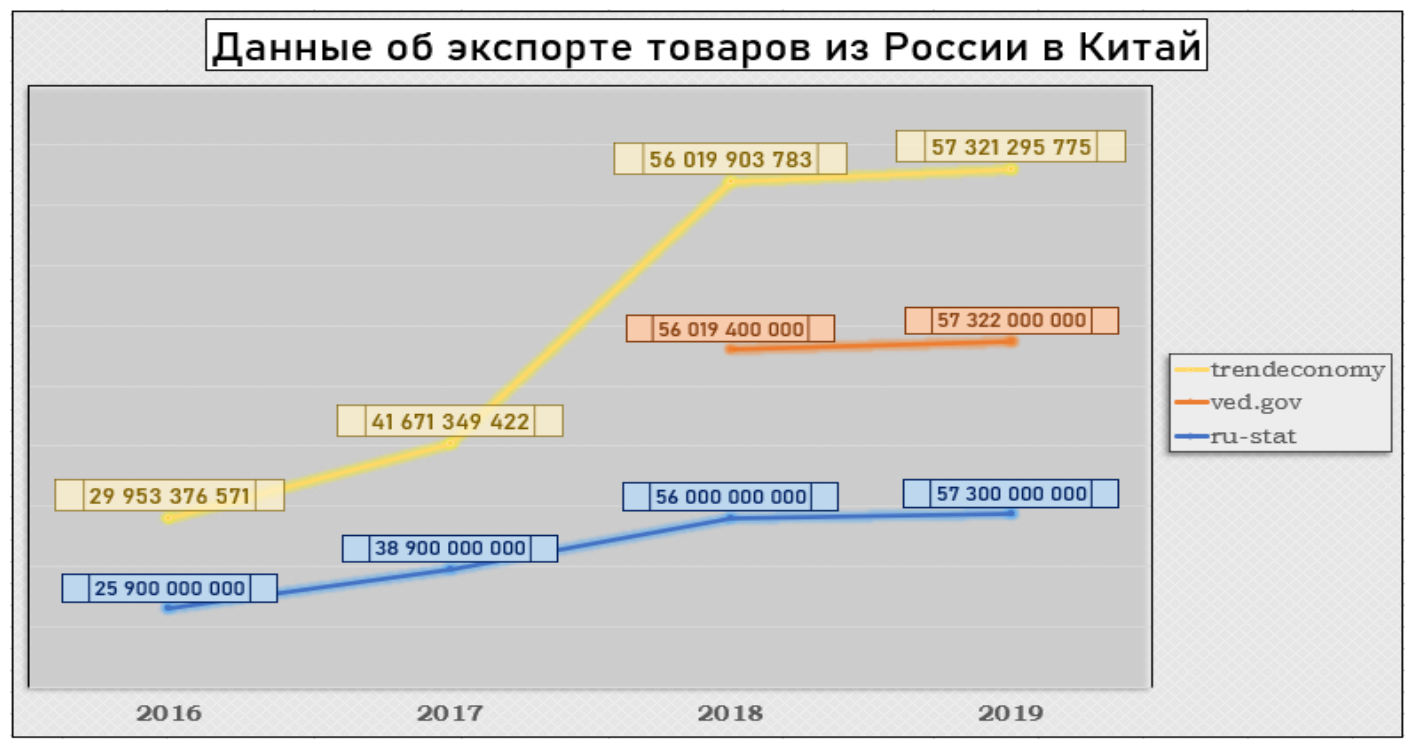

Рисунок 2. Данные об экспорте товаров из России в Китай за 2016-2019 гг., млн. долл. США Источник: составлено автором

расхождение в торговле (экспорт - импорт) по годам. Отчитывающейся стороной, соответственно, принята Российская Федерация, Китай - торговый партнер. На рисунке 3 представлена сумма всего экспорта и импорта в долларах США, на рисунке 4 расхождение (по модулю) в торговле.

С увеличением торговой активности возрастает и уровень расхождения. Показатель расхождения, конечно, положительно коррелирует с общей торговой активностью России и Китая.

Чтобы оценить общую ситуацию и установить причины, возможно повлиявшие на данные расхождения, рассчитаем индекс расхождения в двусторонней торговле (доля расхождения от общего экспорта в страну-партнера). На ри- сунке 5 представлен индекс в динамике.

Показатель варьирует в значительном по сравнении с величиной экспорта из России диапазоне: с максимумом 42.2\% в 2001 году и минимумом $0.67 \%$ в 2017 году. Тенденция с 2010 года нисходящая, что может судить о внедренных мерах по уменьшению расхождения показателей экспорта России в Китай и импорта в Китай из России.

Далее сформулируем причины, которые потенциально могли повлиять на асимметрию данных.

Согласно решению Коллегии Евразийской экономической комиссии от 25 декабря 2018 г. № 210 «Об утверждении Методологии ведения статистики взаимной торговли товарами

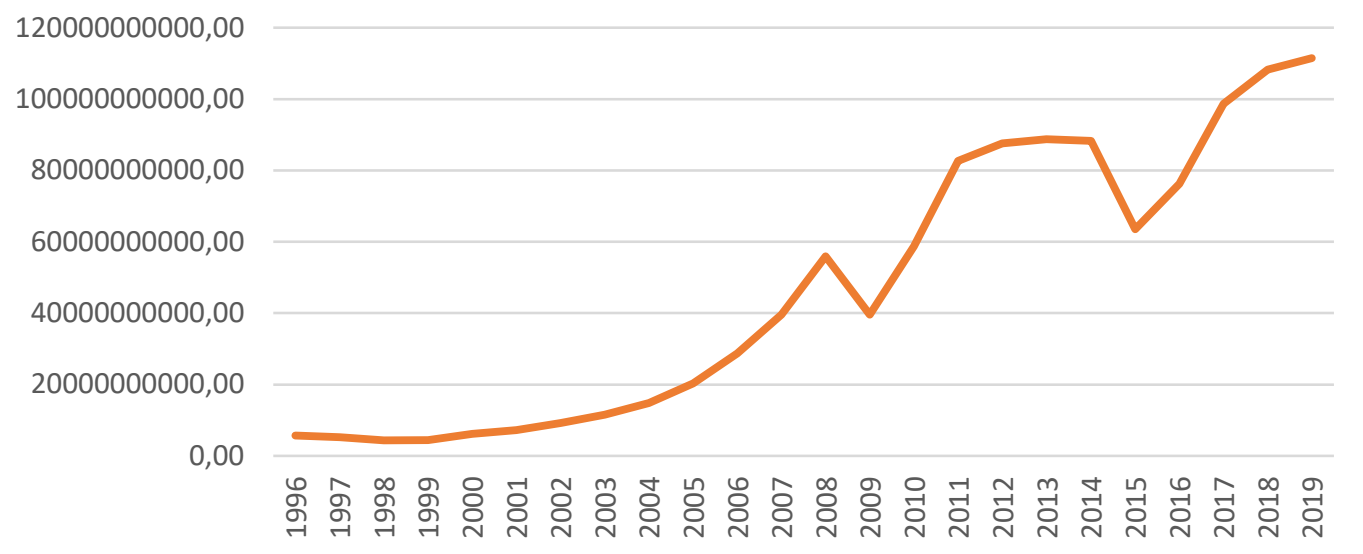

Рисунок 3. Сумма всего экспорта и импорта. Отчитывающаяся страна Россия. Страна-партнер Китай, долл. США

Источник: составлено автором по данным Организации Объединенных Наций [1] 


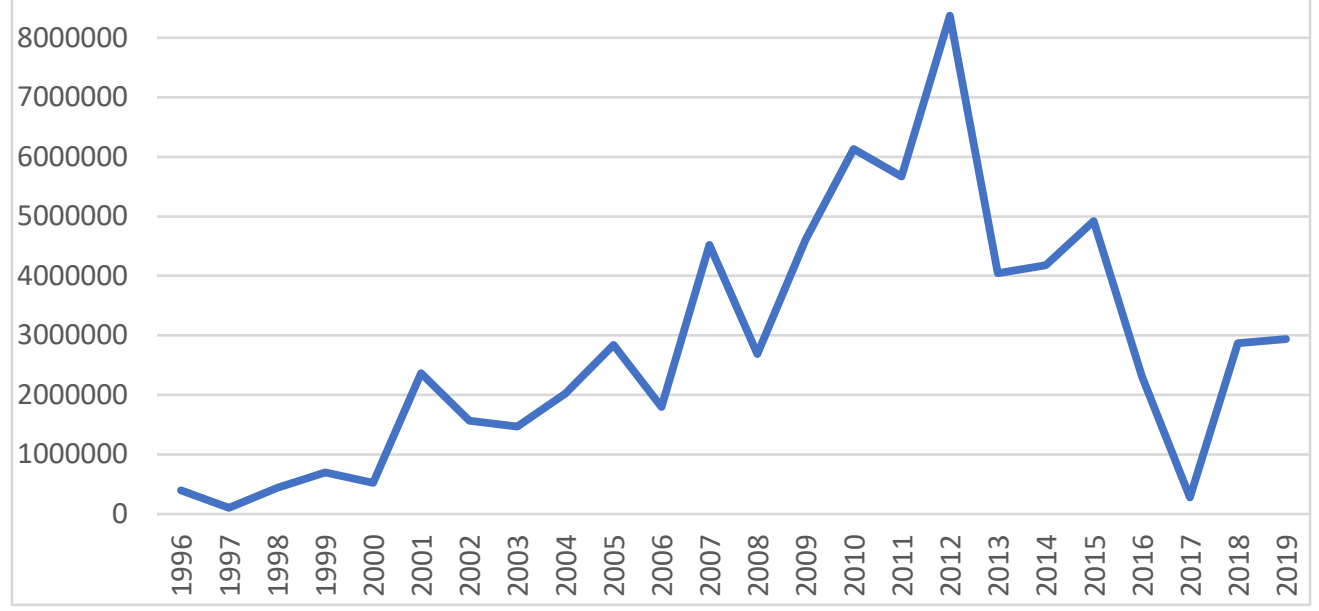

Рисунок 4. Расхождение (по модулю) в торговле. Отчитывающаяся страна Россия. Страна-партнер Китай, долл. США

Источник: составлено автором Организации Объединенных Наций [1]

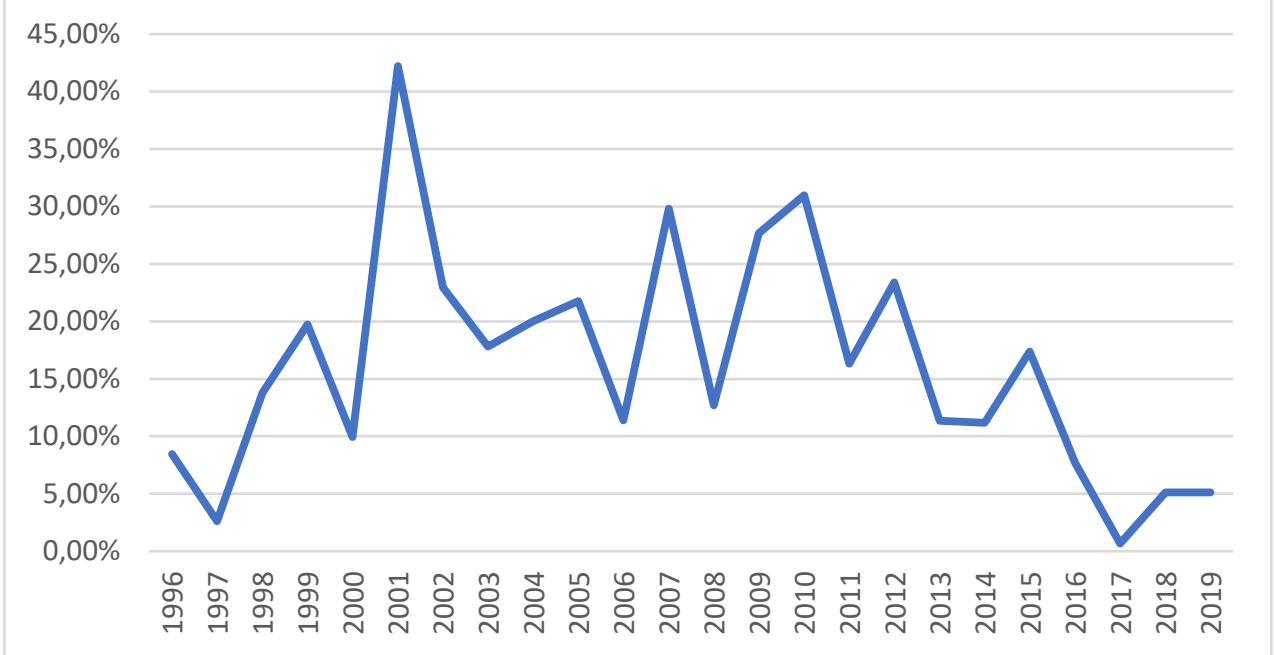

Рисунок 5. Индекс Расхождения в двусторонней торговле,\% Источник: составлено автором Организации Объединенных Наций [1] 


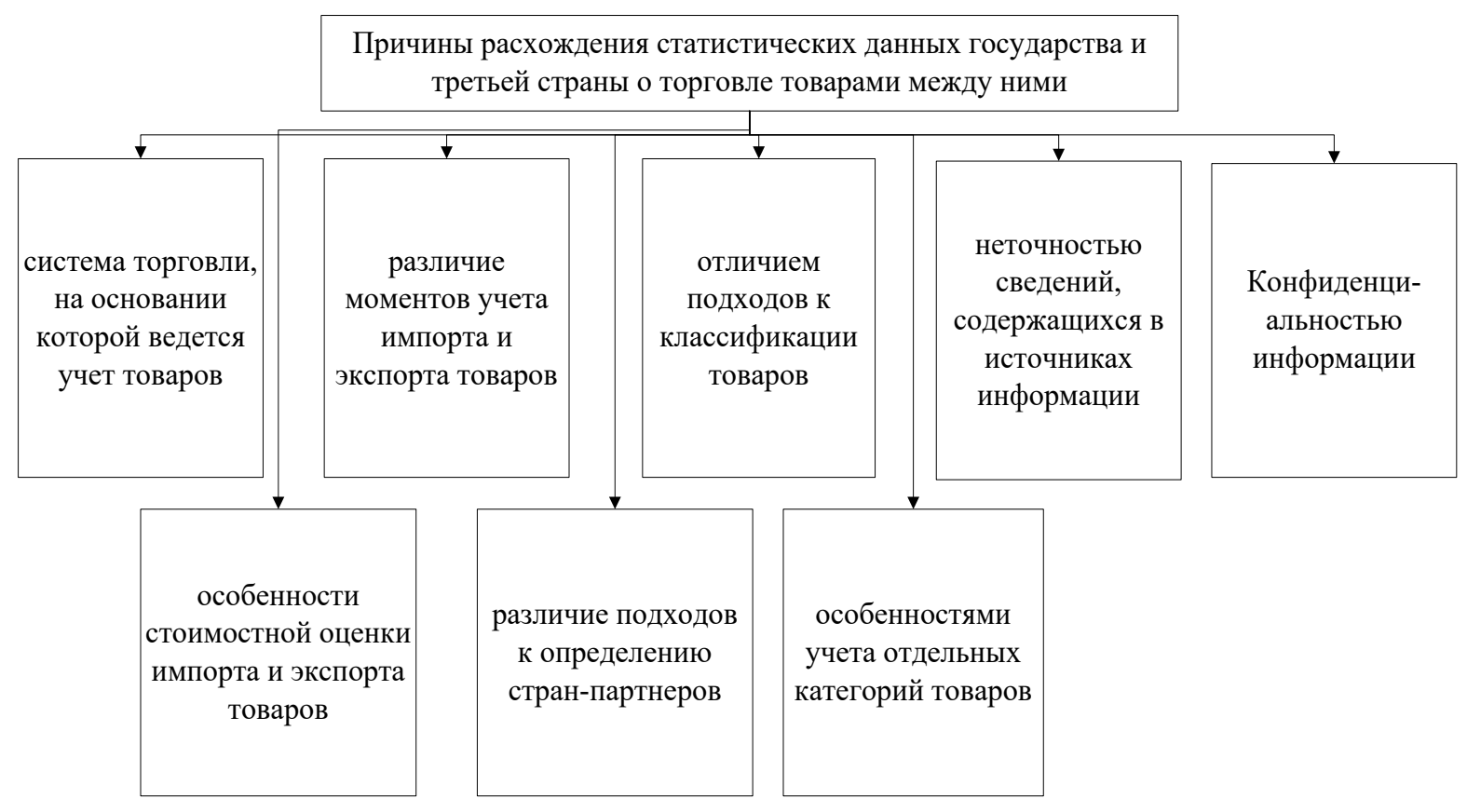

Рисунок 6. Причины расхождения статистических данных государства и третьей страны о торговле товарами между ними

Источник: составлено автором по материалам [8]

государств-членов Евразийского экономического союза и Методологии ведения таможенной статистики внешней торговли товарами государств-членов Евразийского экономического союза» расхождение статистических данных государства-члена и третьей страны о торговле товарами между ними может быть вызвано причинами, представленными на рисунке 6.

Специалисты ФТС установили типичные причины расхождений в данных взаимной торговли и привели отдельные примеры (рисунок 7).

Как показало исследование, существует множество причин, оказывающих влияние на расхождение в экспортных показателях страны-экспортера и импортных показателях стра- ны-торгового партнера. Анализ двусторонних асимметрий полезен для глобальной инициативы по сбалансированности статистики торговли как единого целого из компонентов оценки торговли добавленной стоимостью и анализа глобальных цепочек создания стоимости. Именно понимание относительных значений и динамики показателя расхождения относительно общего экспорта страны-реэкспортера помогают сделать вывод о тенденции, обобщить факторы, а также выделить те из них, которые, подходя по специфику страны, порождают несоответствия. Именно комплекс мер, сформированный и введенный за счет эффективной работы субъектов экономической деятельности, может уменьшить показатель расхождения. 


\section{Разные методологические подходы к Пример: Россия -ЕС}

ведению статистики внешней Товары, ввезенные в страны ЕС и помещенные под режим торговли у России и ее торговых свободного склада, учитываются там в статистике внешней партнеров. В соответствии с- торговли только после их выпуска в свободное обращение (на рекомендациями $\mathrm{OOH}$ в России складе товары могут храниться несколько лет), тогда как в экспорте - используется «общая» система учета России - по дате выпуска товара (принятие таможенным органом торговли, тогда как, например, в решения о выпуске и фактический вывоз товаров с территории странах ЕС и Турции - EАЭС). В результате одни и те же товары учитываются в статистике «спещиальная» в разное время

Разные подходы к классификации товаров, перемещаемых в рамках взаимной торговли. В разных странах один и тот же товар может классифицироваться различными кодами ТН ВЭД (товарная номенклатура внешнеэкономической деятельности)

Включение данных, относящихся к одной и той же сделке, в различные периоды (так называемые переходящие поставки)

\section{Пример: Россия - Корея}

Корейские машинокомплекты, поставляемые для сборки на заводы в Россию, классифицируются корейцами как готовые автомобили, а в России - как набор компонентов (двигатели, кузовы, шасси), каждый из которых имеет свой код. В первом полугодии 2018 года импорт корейских легковых автомобилей в Россию (код 8703) был ниже экспорта Кореи в Россию, а по запчастям для автомобилей импорт России превысил экспорт Кореи

\section{Пример: Россия - США}

Это особенно актуально для торговли удаленных друг от друга стран. Время доставки из России в США и наоборот может сильно варьироваться в зависимости от используемого транспорта или характеристик перевозимого товара. Товары, оформленные на экспорт в конце 2018 года с учетом времени транспортировки, будут учтены в импорте страны-партнера в начале 2019 года

\section{Реэкспорт товаров Пример: Россия - Финляндия}

производства

третьих стран.

Практически все страны включают в свой экспорт товары несобственного происхождения

В импорте принимающей страны (в соответствии с международной методологией учета товаров, рекомендованной ООН) эти товары учитываются по стране $\rightarrow$ происхождения. Этот фактор сильно влияет на расхождения данных таможенной статистики России и стран ЕСВ частности, в 2018 году импорт России из Финляндии был ниже экспорта Финляндии в Россию. Это связано с тем, что около $61 \%$ ввезенных из Финляндии в Россию товаров произведено в других странах ЕС, Китае, США или Японии. Частично они были включены в экспорт Финляндии в Россию, а в импорте России учитывались по стране происхождения

\section{Поставки}

российских

товаров и товаров,

произведенных

страной

торговым

партнером,

территорий

третьих стран

Это особенно характерно для поставок в Россию товаров китайского происхождения с других территорий (ЕС, Гонконг, Республика Корея). В российском импорте они $\rightarrow$ учитываются по стране происхождения (Китай), но в данных Китая об экспорте в Россию не отражаются. Этим обусловлено превышение данных России, в частности, по товарам 84-й группы товарной номенклатуры (реакторы ядерные, котлы, оборудование и механические устройства) и 85-й группы (электрические машины и оборудование, их части)

Пример: Россия - ЕАЭС

Импорт России из Киргизии в 2018 году был ниже экспорта Киргизии в Россию на $\$ 65,8$ млн. Разночтения вызваны проведением киргизской стороной досчетов на ввоз

Осуществление

экспертных

досчетов

и вывоз товаров физическими лицами на основе выборочного обследования

$\rightarrow$ пограничных пунктов пропуска. Результаты досчетов добавляются к объему экспорта и импорта Киргизии с государствами - членами ЕАЭС. В Республике Беларусь также осуществляются досчеты, в частности по овощам, а в Армении для формирования данных взаимной торговли используется дополнительный источник информации - транзитные декларации о перемещении товаров между Россией и

Отнесение сведений

некоторых товарных позициях Арменией через территорию Грузии

конфиденциальной информации

\section{Пример: Россия - Финляндия}

$\kappa \rightarrow$ В России данные о таких товарах включены в общие итоги торговли, а ряд стран, например Финляндия, закрывают информацию о некоторых товарах по просьбам участников ВЭД, что влияет на расхождения в данных

Рисунок 7. Типичные причины расхождений в данных взаимной торговли Источник: составлено автором по материалам [4] 


\section{Библиографический список}

1. База данных Организации Объединенных Наций - Электрон. дан.- Режим доступа: https://comtrade. un.org/data/ (дата обращения 30.05.2021).

2. База данных Trade economy - Электрон. дан. - Режим доступа: https://rendeconomy.ru/data/h2?commodi ty=TOTAL\&reporter=Russia\&trade_flow=Export, Import\&partner=China\&indicator=NW，TQ，TV\&time_peri od=2008,2009,2010,2011,2012,2013,2014,2015,2016,2017,2018,2019 (дата обращения 30.05.2021).

3. Бурцева К.Ю. Анализ преимуществ интеграции для Ирана и ЕАЭС/ Экономические науки - М: 2020.№ 7(188). - С. 109-113.

4. Константинов А. Коварная статистика: откуда расхождения в данных о внешней торговле - Электрон. дан.- Режим доступа: https://www.rbc.ru/opinions/economics/18/06/2019/5d07b0479a794756ffabd7a4. (дата обращения 30.05.2021).

5. Министерство экономического развития - Электрон. дан.- Режим доступа: http://www.ved.gov.ru/ monitoring/foreign_trade_statistics/countries_breakdown/ (дата обращения 30.05.2021).

6. Статистика внешней торговли. По данным ФТС России - Электрон. дан.- Режим доступа: https://ru-stat. com/date-Y2016-2020/RU/export/CN (дата обращения 30.05.2021).

7. Федеральная служба государственной статистики - Электрон. дан. - Режим доступа: https://rosstat.gov.ru/ folder/11193 (дата обращения 30.05.2021).

8. Федеральная таможенная служба - Электрон. дан.- Режим доступа: https://customs.gov.ru/folder/767 (дата обращения 30.05.2021). 